\title{
Expression and clinical significance of cyclooxygenase-2 and interleukin-32 in primary gastric B-cell lymphoma
}

\author{
YINGYING CUI $^{1 *}$, ZHENCHANG SUN $^{1 *}$, XIN LI $^{1}$, CHANGSEN LENG $^{2}$, LEI ZHANG $^{1}$, XIAORUI FU ${ }^{1}$, \\ LING LI $^{1}$, XUDONG ZHANG ${ }^{1}$, YU CHANG ${ }^{1}$, FEIFEI NAN ${ }^{1}$, ZHAOMING LI $^{1}$, JIAQIN YAN ${ }^{1}$, \\ MINGZHI ZHANG ${ }^{1}$, WENCAI $\mathrm{LI}^{3}$, GUANNAN WANG ${ }^{3}$, DANDAN ZHANG ${ }^{3}$ and YAOZHEN MA ${ }^{1}$ \\ ${ }^{1}$ Department of Oncology, The First Affiliated Hospital of Zhengzhou University, Zhengzhou, Henan 450052; \\ ${ }^{2}$ Department of Thoracic Surgery, The Affiliated Cancer Hospital of Zhengzhou University, Zhengzhou, Henan 450008; \\ ${ }^{3}$ Department of Pathology, The First Affiliated Hospital of Zhengzhou University, Zhengzhou, Henan 450052, P.R. China
}

Received November 6, 2014; Accepted May 22, 2015

DOI: $10.3892 / \mathrm{ol} .2015 .3950$

\begin{abstract}
Cyclooxygenase-2 (COX-2) and interleukin-32 (IL-32) expression has been examined in various carcinomas and inflammations, and has been suggested to be significant in tumor progression and prognosis. The present study was conducted to investigate the expression of COX-2 and IL-32 in primary gastric B-cell lymphoma in order to define their clinical significance and their association with Helicobacter pylori (Hp) infection. COX-2 and IL-32 protein expression was detected in 31 primary gastric B-cell lymphoma patients and 19 chronic gastritis patients with immunohistochemistry. COX-2 and IL-32 expression was significantly higher in primary gastric lymphoma (PGL) tissues compared with gastritis tissues (51.6 vs. $21.1 \%$ for COX-2, $\mathrm{P}=0.032$; and 58.1 vs. $26.3 \%$ for $\mathrm{IL}-32, \mathrm{P}=0.029$ ) and was significantly higher in $\mathrm{Hp}^{+}$lymphoma tissues compared with $\mathrm{Hp}^{-}$lymphoma tissues (66.7 vs. $20 \%$ for COX-2, $\mathrm{P}=0.015$; and 71.4 vs. $30 \%$ for $\mathrm{IL}-32, \mathrm{P}=0.029)$. In the $\mathrm{PGL}$ tissues, the expression level of COX-2 was positively correlated with the expression level of IL-32, and the two were each positively correlated with $\mathrm{Hp}$ infection $(\mathrm{P}=0.004$ for COX-2 and IL-32; $\mathrm{P}=0.01$ for COX-2 and Hp infection; and $\mathrm{P}=0.003$ for IL-32 and Hp infection). COX-2 expression was found to be significantly associated $(\mathrm{P}<0.05)$ with an aggressive tumor type, higher expression of $\mathrm{Ki}-67$, frequent lymph node metastasis and advanced stage. IL-32 expression was found to be significantly correlated $(\mathrm{P}<0.05)$ with frequent lymph node metastasis and an advanced stage. The survival
\end{abstract}

Correspondence to: Professor Mingzhi Zhang, Department of Oncology, The First Affiliated Hospital of Zhengzhou University, 1 Jianshe Road, Zhengzhou, Henan 450052, P.R. China

E-mail: mingzhi_zhang1@163.com

*Contributed equally

Key words: primary gastric lymphoma, cyclooxygenase-2, interleukin-32, metastasis, Helicobacter pylori time was longer in the COX-2- and IL-32- lymphoma patients compared with the $\mathrm{COX}-2^{+}$and IL-32+ lymphoma patients, but these differences were not statistically significant. These results suggested that $\mathrm{Hp}$ infection and the expression of COX-2 and IL-32 were closely linked with each other, and that the overexpression of COX-2 and IL-32 was correlated with tumor progression in primary gastric B-cell lymphoma, thus indicating potential novel therapeutic target.

\section{Introduction}

Primary gastric lymphoma (PGL) originates from the stomach, and it is considered that initial symptoms of the disease are located in the stomach or that the primary lesion is located in the stomach (1). PGL is the most common extranodal lymphoma, representing 20-40\% of all extranodal non-Hodgkin's lymphomas (2,3). Diffuse large B-cell lymphoma (DLBCL) accounts for the majority of PGL (59.5\%), followed by the mucosa-associated lymphoid tissue (MALT) type $(37.9 \%)(4,5)$.

As one of the most commonly occurring pathogens, Helicobacter pylori (Hp) infects $\sim 50 \%$ of the global population. Persistent Hp infection leads to chronic and persistent gastritis, and increases the risk of peptic ulcers. More importantly, it is associated with an elevated risk of developing gastric lymphoma and gastric carcinoma (6,7). Cyclooxygenase $(\mathrm{COX})$ is a pivotal enzyme that catalyzes the formation of prostaglandins and other eicosanoids from arachidonic acid. The enhanced expression of COX-2 in the human stomach is associated with $\mathrm{Hp}$ infection, and the development and progression of gastric cancer $(8,9)$. Interleukin-32 (IL-32) is a newly identified proinflammatory cytokine that is produced by immune cells (10). IL-32 is important in a number of inflammatory or neoplastic disorders. The expression of this cytokine has been demonstrated to correlate with the severity of disease in gastritis, lung adenocarcinoma and rheumatoid arthritis, and is reported to be more likely expressed in $\mathrm{Hp}^{+}$ gastritis tissues (11-13). Lee et al (14) reported that the overexpression of COX-2 increased the expression level of IL-32 and that this expression could be blocked by the selective COX-2 inhibitor in papillomavirus-induced cervical cancer, 
while Li et al (15) found the same phenomenon in influenza A virus-infected patients.

However, the association between COX-2, IL-32 and Hp infection, and the clinical significance of COX-2 and IL-32 expression in PGL remain unknown. In the present study, COX-2 and IL-32 expression was detected in biopsy specimens from patients with primary gastric B-cell lymphoma in order to define their clinical significance and their association with Hp infection.

\section{Materials and methods}

Patients. Specimens from 18 primary gastric DLBCL patients ( 8 males and 10 females; mean age, 47 years; age range, 18-68 years), 13 primary gastric MALT lymphoma patients (4 males and 9 females; mean age, 52 years; age range, 22-76 years) and 19 gastritis patients (11 males and 8 females; mean age, 46 years; age range, 19-69 years) were obtained from the First Affiliated Hospital of Zhengzhou University (Zhengzhou, Henan, China) between April 2009 and April 2014. The pathological specimens were obtained from endoscopic biopsies and surgical resections, and were formalin-fixed and paraffin-embedded. Prior to obtaining the pathological specimens, the patients had not been treated with radiotherapy or chemotherapy. All specimens were reviewed by two pathologists separately. All cases identified from the database satisfied the PGL diagnostic criteria defined by Lewin et al (16) and were classified based on morphological and immunophenotypic criteria according to the 2008 World Health Organization (WHO) classification of hematopoietic and lymphoid tumors (17). The clinical staging of PGL patients was performed according to the Lugano International Conference classification (I, II1, II2, IIE and IV), which was proposed as a modified version of the Ann Arbor criteria for gastrointestinal lymphoma (18). Hp infection was determined by the ${ }^{14} \mathrm{C}$-urea breath test or histological features. The present study was approved by the Medical Ethics Committee of Zhengzhou University and written informed consent was obtained from all patients.

Immunohistochemistry. For immunohistochemistry, the streptavidin-peroxidase staining method was used on $4-\mu \mathrm{m}$ thick formalin-fixed and paraffin-embedded tissue sections, including PGL and gastritis tissues. The sections were deparaffinied and dehydrated in xylene and graded ethanol solutions. Antigen retrieval was performed in citrate buffer ( $\mathrm{pH}, 6.0)$. Following incubation overnight with polyclonal rabbit anti-human COX-2 antibody (1:150 dilution) and polyclonal rabbit anti-human IL-32 antibody (1:120 dilution), slides were treated with horseradish peroxidase-conjugated secondary mouse anti-rabbit IgG antibodies (1:250 and 1:200 dilutions), followed by substrate 3,3'-diaminobenzidine tetrahydrochloride (all from ZSGB-BIO, Beijing, China). The slides were then counterstained with hematoxylin and covered with neutral balsam. Phosphate-buffered saline was used as a blank control. COX-2 and IL-32 expression in the gastritis tissues served as positive controls.

Evaluation of immunohistochemical staining. COX-2 and IL-32 expression was determined by staining intensity and the percentage of positive cells. Staining intensity was graded as follows: No expression, 0; weak expression, 1; moderate expression, 2; and strong expression, 3. The percentage of positive cells was graded as follows: Positive cells in $<5 \%$ of the total tumor area, $0 ; 5-25 \%, 1 ; 25-50 \%, 2 ; 50-75 \%, 3$; and $>75 \%, 4$. The immunohistochemistry score was calculated by multiplying the two scores, and ranged from 0 to 12 . A score of 9-12 was considered as strong immunoreactivity, 5-8 as moderate, $1-4$ as weak and 0 as negative. Strong and moderate immunoreactivity were considered as high expression, whereas weak and negative immunoreactivity were regarded as low expression (19).

Statistical analysis. $\chi^{2}$ tests were used to compare the statistical differences between groups. The correlation between COX-2 and IL-32 expression and Hp infection was assessed by Spearman's rank test. Overall survival (OS) time was calculated from the date of diagnosis to mortality or the last date of follow-up. The OS rate was estimated using the Kaplan-Meier method and was compared with the log-rank test. $\mathrm{P}<0.05$ was used to indicate a statistically significant difference. SPSS version 20.0 (IBM SPSS, Armonk, NY, USA) was used for the statistical analysis.

\section{Results}

Expression of COX-2 and IL-32 in gastric lymphoma tissue and gastritis tissue. Fig. 1 shows the different staining intensities. The high expression rates of COX-2 were $51.6 \%(16 / 31)$ and $21.1 \%$ (4/19) in the PGL and gastritis groups, respectively $(\mathrm{P}=0.032)$ (Table I), and the high expression rates of IL-32 were $58.1 \%(18 / 31)$ and $26.3 \%(5 / 19)$ in PGL and gastritis groups, respectively $(\mathrm{P}=0.029)$. The $\mathrm{PGL}$ group showed a significantly higher expression level of COX-2 and IL-32 compared with the gastritis group.

Correlation between COX-2, IL-32 and Hp infection in lymphoma tissues. In the PGL tissues, Hp infection was positively correlated with COX-2 (P=0.01) and IL-32 ( $\mathrm{P}=0.003)$ expression. In addition, $\mathrm{COX}-2$ expression was positively associated with IL-32 expression ( $\mathrm{P}=0.004)$ (Fig. 2) in the PGL tissues.

Correlation of COX-2 and IL-32 expression with clinicopathological characteristics. Table II summarizes the association between the expression of COX-2 and IL-32 and the clinicopathological characteristics of the PGL patients. The overexpression of COX-2 was significantly correlated $(\mathrm{P}<0.05)$ with an aggressive tumor type, higher expression of $\mathrm{Ki}-67$, greater Hp infection, frequent lymph node metastasis and an advanced stage. There was no significant correlation between COX-2 and other variables, including gender, age, international prognostic index score, lactate dehydrogenase level and 32 -microglobulin level. IL-32 expression was found to be significantly correlated with greater $\mathrm{Hp}$ infection, frequent lymph node metastasis and an advanced stage.

Survival analysis. The prognostic value of COX-2 and IL-32 expression on OS was evaluated in all lymphoma patients. The mean survival time for the 31 patients was 45 months (Fig. 3A). The 4-year OS rates for the COX $-2^{+}$and $\mathrm{COX}-2^{-}$patients were 
Table I. Expression of COX-2 and IL-32 in primary gastric lymphoma and gastritis tissues.

\begin{tabular}{|c|c|c|c|c|c|c|}
\hline \multirow[b]{2}{*}{ Group } & \multicolumn{3}{|c|}{ COX-2 expression } & \multicolumn{3}{|c|}{ IL-32 expression } \\
\hline & High, n (\%) & Low, n (\%) & P-value & High, n (\%) & Low, n (\%) & P-value \\
\hline Lymphoma tissue & $16(51.6)$ & $15(48.4)$ & 0.032 & $18(58.1)$ & $13(41.9)$ & 0.029 \\
\hline Gastritis tissue & $4(21.1)$ & 15 (78.9) & & $5(26.3)$ & $14(73.7)$ & \\
\hline
\end{tabular}

COX-2, cyclooxygenase-2; IL-32, interleukin-32.

Table II. Correlation between COX-2 and IL-32 expression and the clinicopathological characteristics of primary gastric lymphoma patients.

\begin{tabular}{|c|c|c|c|c|c|c|c|}
\hline \multirow[b]{2}{*}{ Variables } & \multirow[b]{2}{*}{ Total, $\mathrm{n}$} & \multicolumn{3}{|c|}{ COX-2 expression } & \multicolumn{3}{|c|}{ IL-32 expression } \\
\hline & & High, $n$ & Low, $\mathrm{n}$ & P-value & High, $n$ & Low, $\mathrm{n}$ & P-value \\
\hline \multicolumn{8}{|l|}{ Gender } \\
\hline Male & 12 & 5 & 7 & 0.379 & 9 & 3 & 0.129 \\
\hline Female & 19 & 11 & 8 & & 9 & 10 & \\
\hline \multicolumn{8}{|l|}{ Age, years } \\
\hline$\geq 60$ & 11 & 6 & 5 & 0.809 & 5 & 6 & 0.291 \\
\hline$<60$ & 20 & 10 & 10 & & 13 & 7 & \\
\hline \multicolumn{8}{|c|}{ Histological type } \\
\hline PG-DLBCL & 18 & 13 & 5 & 0.007 & 12 & 6 & 0.253 \\
\hline PG-MALT & 13 & 3 & 10 & & 6 & 7 & \\
\hline \multicolumn{8}{|l|}{ IPI score } \\
\hline$<2$ & 23 & 11 & 12 & 0.474 & 13 & 10 & 0.768 \\
\hline$\geq 2$ & 8 & 5 & 3 & & 5 & 3 & \\
\hline \multicolumn{8}{|l|}{ LDH, U/l } \\
\hline$<245$ & 27 & 13 & 14 & 0.316 & 15 & 12 & 0.462 \\
\hline$\geq 245$ & 4 & 3 & 1 & & 3 & 1 & \\
\hline \multicolumn{8}{|l|}{ Hp infection } \\
\hline Positive & 21 & 14 & 7 & 0.015 & 15 & 6 & 0.029 \\
\hline Negative & 10 & 2 & 8 & & 3 & 7 & \\
\hline \multicolumn{8}{|l|}{ ß2-MG, mg/l } \\
\hline$<3$ & 6 & 5 & 1 & 0.083 & 4 & 2 & 0.634 \\
\hline$\geq 3$ & 25 & 11 & 14 & & 14 & 11 & \\
\hline \multicolumn{8}{|l|}{$\mathrm{Ki}-67, \%$} \\
\hline$<60$ & 16 & 5 & 11 & 0.019 & 9 & 7 & 0.833 \\
\hline$\geq 60$ & 15 & 11 & 4 & & 9 & 6 & \\
\hline \multicolumn{8}{|c|}{ Lymph node metastasis } \\
\hline Yes & 19 & 13 & 6 & 0.018 & 14 & 5 & 0.027 \\
\hline No & 12 & 3 & 9 & & 4 & 8 & \\
\hline \multicolumn{8}{|l|}{ Stage } \\
\hline I-II1 & 17 & 6 & 11 & 0.045 & 7 & 10 & 0.036 \\
\hline II2-IV & 14 & 10 & 4 & & 11 & 3 & \\
\hline
\end{tabular}

COX-2, cyclooxygenase-2; IL-32, interleukin-32; PG-DLBCL, primary gastric diffuse large B-cell lymphoma; PG-MALT, primary gastric mucosa-associated lymphoid tissue; IPI, international prognostic index; LDH, lactate dehydrogenase; Hp, Helicobacter pylori; $\beta 2-\mathrm{MG}, \beta 2$-microglobulin. 

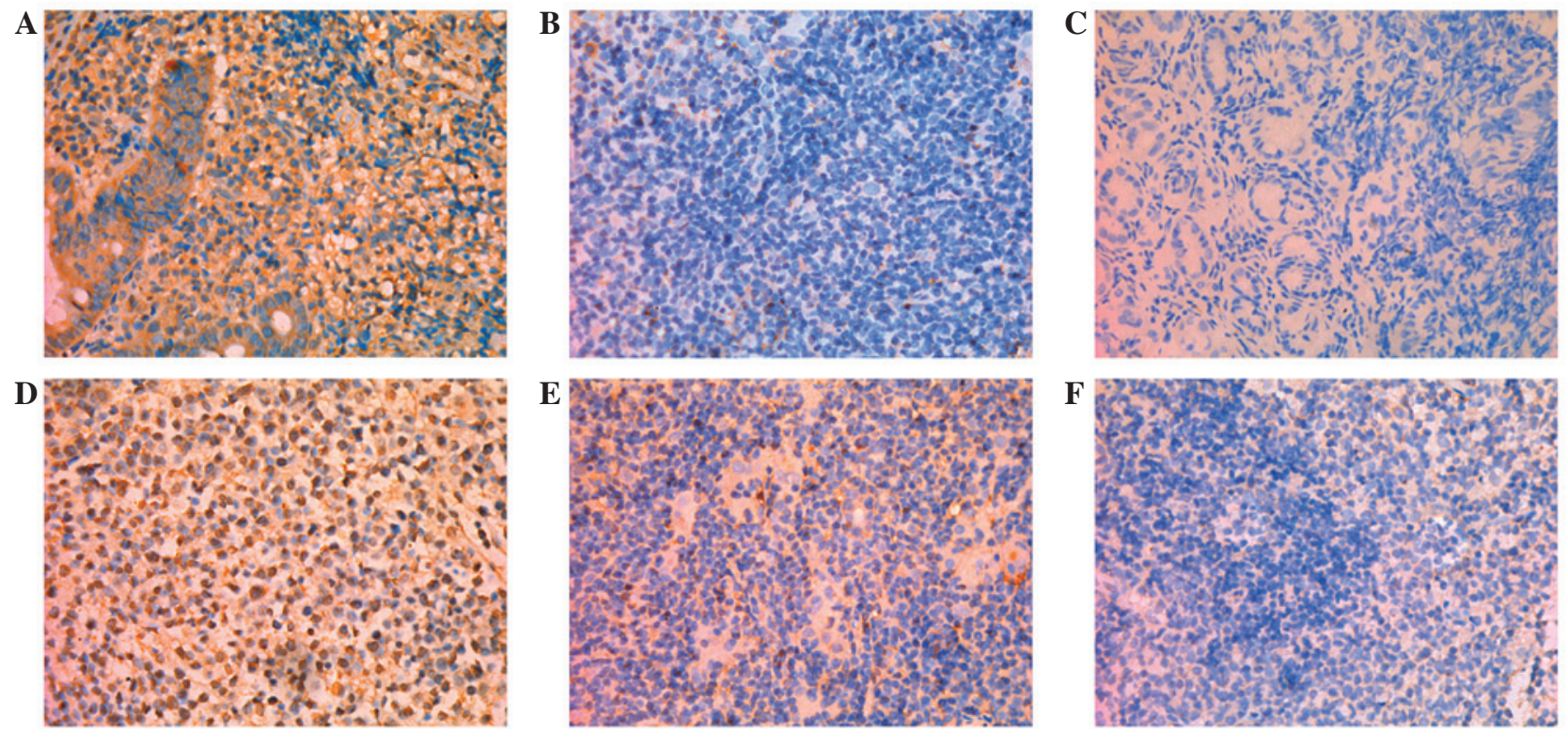

Figure 1. Representative immunohistochemical staining of (A-C) COX-2 and (D-F) IL-32 in primary gastric B-cell lymphoma tissues: (A and D) High expression cases, (B and E) low expression cases, and ( $\mathrm{C}$ and $\mathrm{F}$ ) negative cases (magnification, $\mathrm{x} 400$ ). COX-2, cyclooxygenase-2; IL-32, interleukin-32.

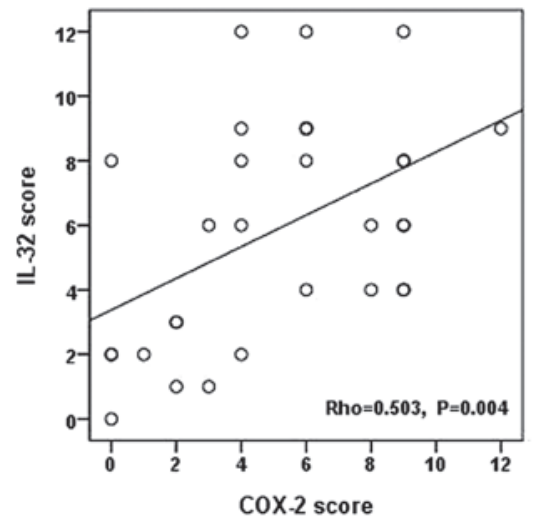

Figure 2. COX-2 expression is positively correlated with IL-32 expression in primary gastric lymphoma tissues. COX-2, cyclooxygenase-2; IL-32, interleukin-32.

with those patients with lower COX-2 and IL-32 expression levels, but the differences in the various groups showed no statistical significance.

\section{Discussion}

PGL is a unique disease and has a variety of pathological types, and DLBCL and MALT lymphoma account for the majority of PGLs $(97.4 \%)(4,5)$. Hp infection is important in the development of PGL. Therefore, Hp eradication leads to remission of the disease. A number of previous studies have confirmed the effectiveness of Hp eradication in early-stage gastric MALT lymphoma $(20,21)$. A recent study also demonstrated that patients with $\mathrm{Hp}^{+}$early-stage DLBCL could achieve complete pathological remission via Hp eradication (22). Studies have found that there is a clinical correlation between COX-2 expression and prognostic factors in lymphoma patients (23-25), and that IL-32 is also closely linked with T-cell lymphoma and $\mathrm{Hp}^{+}$ gastritis $(12,26)$. However, the expression of COX -2 and IL-32,
A

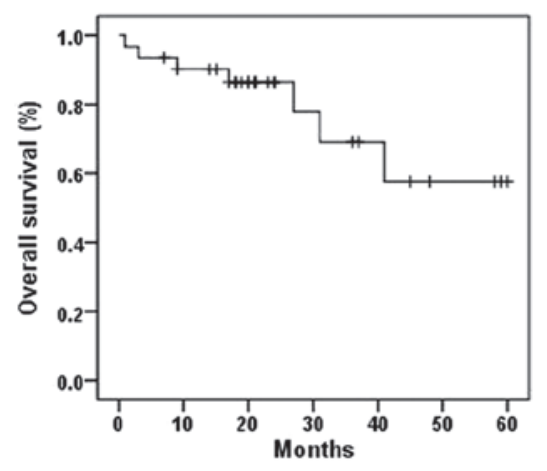

B

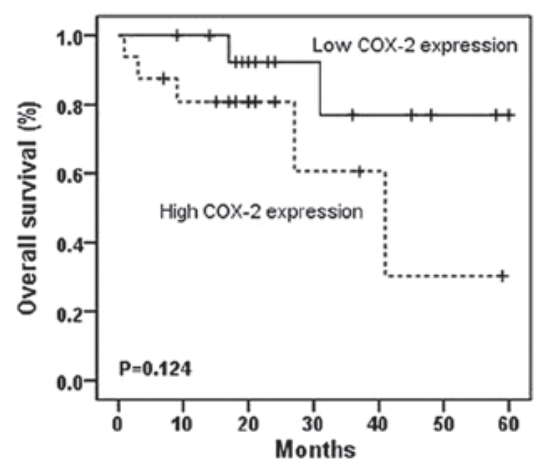

C

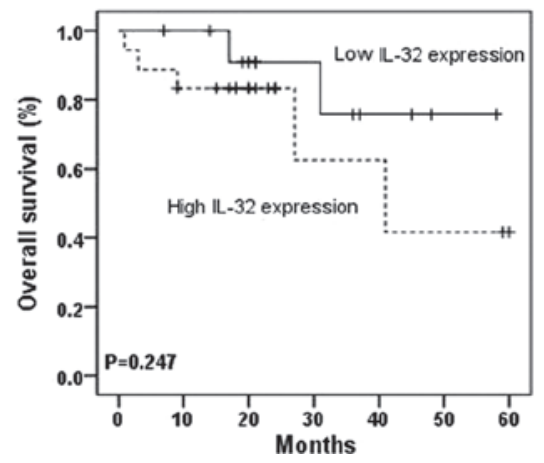

Figure 3. OS of 31 patients with primary gastric B-cell lymphoma (A), and the role of COX-2 (B) and IL-32 (C) expression levels in OS. COX-2, cyclooxygenase-2; IL-32, interleukin-32; OS, overall survival. 
and the correlation between COX-2 and IL-32 expression and clinicopathological features in PGL patients remains unclear.

In the present study, it was observed that the expression levels of COX-2 $(\mathrm{P}=0.032)$ and IL-32 $(\mathrm{P}=0.029)$ in the PGL tissues were significantly higher than those in the gastritis tissues. Miettinen et al suggested that lymphocytic gastritis was a possible precursor state of gastric lymphoma (27). Bartchewsky et al reported that the inflammatory response to $\mathrm{Hp}$ infection upregulated the expression of COX-2 in patients with chronic gastritis (28). Peng et al showed that Hp infection also induced the upregulation of IL-32, which played an important role in the pathogenesis of Hp-related gastritis (12). The inflammatory response induced the expression of COX-2 and IL-32 in the gastritis tissue, and the present data suggested that the expression of COX-2 and IL-32 may play an important role in the process of gastritis transforming into gastric lymphoma. In the present study, the expression levels of COX-2 and IL-32 were shown to be significantly higher in the $\mathrm{Hp}^{+} \mathrm{PGL}$ patients than in the $\mathrm{Hp}^{-} \mathrm{PGL}$ patients (67 vs. $20 \%, \mathrm{P}=0.015$ for $\mathrm{COX}-2$; and 71 vs. $30 \%, P=0.029$ for IL-32), suggesting that $\mathrm{COX}-2$ and IL-32 not only played a significant role in $\mathrm{Hp}^{+}$gastritis, but also in $\mathrm{Hp}^{+}$gastric lymphoma. In the gastric lymphoma tissues, the $\mathrm{Hp}$ infection-induced inflammatory response identically upregulated the expression of COX-2 and IL-32.

The COX-2 enzyme mediates the inflammatory process and is frequently overexpressed in various tumors $(9,29)$. IL-32 is a newly identified proinflammatory cytokine that is produced by immune cells (10). Lee et al (14) showed that COX-2 and IL-32 were evaluated in human papillomavirus-positive cervical cancer. The overexpression of COX-2 resulted in an increased IL-32 expression level, and this expression was blocked by the application of the selective COX-2 inhibitor. In the present study, IL-32 expression was significantly associated with COX-2 expression, which we hypothesize may mean that IL-32 is inseparable from the expression of COX-2 when it functions in the development of PGL. Further investigative experiments should be performed in the future.

Based on previous studies, the contribution of COX-2 to carcinogenesis is believed to be through the increase in the production of prostaglandins, the conversion of procarcinogens to carcinogens, the inhibition of apoptosis, the promotion of angiogenesis, the modulation of inflammation and immune function, and the increase in tumor cell invasiveness (30). Kato et al reported that COX-2 expression was significantly correlated with the WHO grade and tumor progression of meningioma (31). Al-Moundhri et al also suggested that COX-2 expression was significantly correlated with lymph node involvement and high microvascular density in gastric cancer (32). In the present study, there was a significant association between COX-2 expression and an aggressive tumor type, higher expression of $\mathrm{Ki}-67$, frequent lymph node metastasis and advanced stage, suggesting that the overexpression of COX-2 was correlated with the formation and progression of PGL. Ishigami et al reported that IL-32 was a poor prognostic marker for gastric cancer and was positively correlated with tumor depth and lymph node metastasis (33). The present data demonstrated that IL-32 expression was significantly correlated with frequent lymph node metastasis and advanced stage, which further confirmed that COX-32 and IL-32 played important roles in the development and progression of PGL.
In the present study, the patients with high COX-2 and IL-32 expression levels had a poor prognosis compared with the patients with low COX-2 and IL-32 expression levels, but the differences in the various groups showed no statistical significance. Koh et al found that COX-2 was an independent prognostic factor for OS in patients with Hodgkin's lymphoma (34), while Hazar et al found that there was no significant correlation between COX-2 expression and survival in lymphoma patients (23). Due to the limited sample size, the correlation between COX-2 and IL-32 expression and survival requires confirmation.

In conclusion, the present study found upregulated COX-2 and IL-32 expression in primary gastric B-cell lymphoma. This study confirmed that COX-2 expression was associated with IL-32 expression, and that expression of each was then correlated with $\mathrm{Hp}$ infection in PGL patients. Furthermore, COX-2 and IL-32 expression may be important in the development of PGL, but the reliability of the present results was restricted by the sample size. The correlations between COX-2 and IL-32 expression and prognosis require further confirmatory trials. The molecular basis for the expression of COX-2 and IL-32 and their roles in the transformation of $\mathrm{Hp}$-associated gastritis to gastric lymphoma requires future careful investigation in follow-up studies.

\section{Acknowledgements}

This study was supported through the assistance of the Department of Medical Records and the Digestive Endoscopy Center in the First Affiliated Hospital of Zhengzhou University.

\section{References}

1. Huang J, Jiang W, Xu R, Huang H, Lv Y, Xia Z, Sun X, Guan Z, Lin $\mathrm{T}$ and $\mathrm{Li} \mathrm{Z}$ : Primary gastric non-Hodgkin's lymphoma in Chinese patients: Clinical characteristics and prognostic factors. BMC Cancer 10: 358, 2010.

2. Psyrri A, Papageorgiou S and Economopoulos T: Primary extranodal lymphomas of stomach: Clinical presentation, diagnostic pitfalls and management. Ann Oncol 19: 1992-1999, 2008.

3. Nakamura S, Matsumoto T, Iida M, Yao T and Tsuneyoshi M: Primary gastrointestinal lymphoma in Japan: A clinicopathologic analysis of 455 patients with special reference to its time trends. Cancer 97: 2462-2473, 2003.

4. D'Amore F, Christensen BE, Thorling K, Pedersen M, Jensen MK, Boesen AM, Andersen E, Johansen P and Mortensen LS: Incidence, presenting features and prognosis of low-grade B-cell non-Hodgkin's lymphomas. Population-based data from a Danish lymphoma registry. Leuk Lymphoma 12: 69-77, 1993.

5. Koch P, Probst A, Berdel WE, Willich NA, Reinartz G, Brockmann J, Liersch R, del Valle F, Clasen H, Hirt C, et al: Treatment results in localized primary gastric lymphoma: Data of patients registered within the German multicenter study (GIT NHL 02/96). J Clin Oncol 23: 7050-7059, 2005.

6. Wang F,Meng W, Wang B and QiaoL: Helicobacterpylori-induced gastric inflammation and gastric cancer. Cancer Lett 345: 196-202, 2014.

7. Campuzano-Maya G: Hematologic manifestations of Helicobacter pylori infection. World J Gastroenterol 20: 12818-12838, 2014.

8. Konturek PC, Hartwich A, Zuchowicz M, Labza H, Pierzchalski P, Karczewska E, Bielanski W, Hahn EG and Konturek SJ: Helicobacter pylori, gastrin and cyclooxygenases in gastric cancer. J Physiol Pharmacol 51: 737-749, 2000.

9. Yamac D, Ayyildiz T, Coskun U, Akyürek N, Dursun A, Seckin S and Koybasioglu F: Cyclooxygenase-2 expression and its association with angiogenesis, Helicobacter pylori, and clinicopathologic characteristics of gastric carcinoma. Pathol Res Pract 204: 527-536, 2008 . 
10. Akdis M, Burgler S, Crameri R, Eiwegger T, Fujita H, Gomez E, Klunker S, Meyer N, O'Mahony L, Palomares O, et al: Interleukins, from 1 to 37, and interferon- $\gamma$ : receptors, functions, and roles in diseases. J Allergy Clin Immunol 127: 701-721.e701-770, 2011

11. Zeng Q, Li S, Zhou Y, Ou W, Cai X, Zhang L, Huang W, Huang L and Wang Q: Interleukin-32 contributes to invasion and metastasis of primary lung adenocarcinoma via NF- $\kappa \mathrm{B}$ induced matrix metalloproteinases 2 and 9 expression. Cytokine 65: 24-32, 2014.

12. Peng LS, Zhuang Y, Li WH, Zhou YY, Wang TT, Chen N, Cheng P, Li BS, Guo H, Yang SM, et al: Elevated interleukin-32 expression is associated with Helicobacter pylori-related gastritis. PLoS One 9: e88270, 2014.

13. Gui M, Zhang H, Zhong K, Li Y, Sun J and Wang L: Clinical significance of interleukin-32 expression in patients with rheumatoid arthritis. Asian Pac J Allergy Immunol 31: 73-78, 2013.

14. Lee S, Kim JH, Kim H, Kang JW, Kim SH, Yang Y, Kim J, Park J, Park S, Hong J, et al: Activation of the interleukin-32 pro-inflammatory pathway in response to human papillomavirus infection and over-expression of interleukin-32 controls the expression of the human papillomavirus oncogene. Immunology 132: 410-420, 2011

15. Li W, Liu Y, Mukhtar MM, Gong R, Pan Y, Rasool ST, Gao Y, Kang L, Hao Q, Peng G, et al.: Activation of interleukin-32 pro-inflammatory pathway in response to influenza A virus infection. PLoS One 3: e1985, 2008.

16. Lewin KJ, Ranchod M and Dorfman RF: Lymphomas of the gastrointestinal tract: A study of 117 cases presenting with gastrointestinal disease. Cancer 42: 693-707, 1978.

17. Tomonaga M: Outline and direction of revised WHO classification of Tumors of Haematopoietic and Lymphoid Tissues. Rinsho Ketsueki 50: 1401-1406, 2009 (In Japanese).

18. Rohatiner A, d'Amore F, Coiffier B, Crowther D, Gospodarowicz M, Isaacson P, Lister TA, Norton A, Salem P, Shipp M et al: Report on a workshop convened to discuss the pathological and staging classifications of gastrointestinal tract lymphoma. Ann Oncol 5: 397-400, 1994.

19. Li Y, Li S, Sun D, Song L and Liu X: Expression of 15-hydroxyprostaglandin dehydrogenase and cyclooxygenase-2 in non-small cell lung cancer: Correlations with angiogenesis and prognosis. Oncol Lett 8: 1589-1594, 2014.

20. Bayerdörffer E, Neubauer A, Rudolph B, Thiede C, Lehn N, Eidt S and Stolte M; MALT Lymphoma Study Group: Regression of primary gastric lymphoma of mucosa-associated lymphoid tissue type after cure of Helicobacter pylori infection. Lancet 345: 1591-1594, 1995

21. Wündisch T, Thiede C, Morgner A, Dempfle A, Günther A, Liu H, Ye H, Du MQ, Kim TD, Bayerdörffer E, et al: Long-term follow-up of gastric MALT lymphoma after Helicobacter pylori eradication. J Clin Oncol 23: 8018-8024, 2005.

22. Kuo SH, Yeh KH, Wu MS, Lin CW, Hsu PN, Wang HP, Chen LT and Cheng AL: Helicobacter pylori eradication therapy is effective in the treatment of early-stage $H$ pylori-positive gastric diffuse large B-cell lymphomas. Blood 119: 4838-4844, quiz 5057, 2012.
23. Hazar B, Ergin M, Seyrek E, Erdoğan S, Tuncer I and Hakverdi S: Cyclooxygenase-2 (Cox-2) expression in lymphomas. Leuk Lymphoma 45: 1395-1399, 2004.

24. Paydas S, Ergin M, Seydaoglu G, Erdogan S and Yavuz S: Prognostic (corrected) significance of angiogenic/lymphangiogenic, anti-apoptotic, inflammatory and viral factors in 88 cases with diffuse large B cell lymphoma and review of the literature. Leuk Res 33: 1627-1635, 2009.

25. Wun T, McKnight $\mathrm{H}$ and Tuscano JM: Increased cyclooxygenase-2 (COX-2): A potential role in the pathogenesis of lymphoma. Leuk Res 28: 179-190, 2004.

26. Suga H, Sugaya M, Miyagaki T, Kawaguchi M, Fujita H, Asano Y, Tada Y, Kadono T and Sato S: The role of IL-32 in cutaneous T-cell lymphoma. J Invest Dermatol 134: 1428-1435, 2014.

27. Miettinen A, Karttunen TJ and Alavaikko M: Lymphocytic gastritis and Helicobacter pylori infection in gastric lymphoma. Gut 37: 471-476, 1995.

28. Bartchewsky W Jr, Martini MR, Masiero M, Squassoni AC, Alvarez MC, Ladeira MS, Salvatore D, Trevisan M, Pedrazzoli J Jr and Ribeiro ML: Effect of Helicobacter pylori infection on IL-8, IL-1 $\beta$ and COX-2 expression in patients with chronic gastritis and gastric cancer. Scand J Gastroenterol 44: 153-161, 2009.

29. Denkert C, Winzer KJ, Müller BM, Weichert W, Pest S, Köbel M, Kristiansen G, Reles A, Siegert A, Guski H, et al: Elevated expression of cyclooxygenase- 2 is a negative prognostic factor for disease free survival and overall survival in patients with breast carcinoma. Cancer 97: 2978-2987, 2003.

30. Li HL, Sun BZ and Ma FC: Expression of COX-2, iNOS, p53 and $\mathrm{Ki}-67$ in gastric mucosa-associated lymphoid tissue lymphoma. World J Gastroenterol 10: 1862-1866, 2004.

31. Kato Y, Nishihara H, Mohri H, Kanno H, Kobayashi H, Kimura T, Tanino M, Terasaka S and Tanaka S: Clinicopathological evaluation of cyclooxygenase- 2 expression in meningioma: Immunohistochemical analysis of 76 cases of low and high-grade meningioma. Brain Tumor Pathol 31: 23-30, 2014.

32. Al-Moundhri MS, Al-Hadabi I, Al-Mawaly K, Kumar S, Al-Lawati FA, Bhatnager G, Kuruvila S, Al-Hamdani A, El-Sayed SM and Al-Bahrani B: Prognostic significance of cyclooxygenase-2, epidermal growth factor receptor 1 , and microvascular density in gastric cancer. Med Oncol 29: 1739-1747, 2012

33. Ishigami S, Arigami T, Uchikado Y, Setoyama T, Kita Y, Sasaki K, Okumura H, Kurahara H, Kijima Y, Harada A, et al: IL-32 expression is an independent prognostic marker for gastric cancer. Med Oncol 30: 472, 2013.

34. Koh YW, Park C, Yoon DH, Suh C and Huh J: Prognostic significance of COX-2 expression and correlation with Bcl-2 and VEGF expression, microvessel density, and clinical variables in classical Hodgkin lymphoma. Am J Surg Pathol 37: 1242-1251, 2013. 